\title{
Gold-Containing Dendrimers: A New Class of Macromolecules
}

\author{
Oriol Rossell and Miquel Seco \\ Departament de Quimica Inorgànica, Universitat de Barcelona, Martí i Franquès, \\ 1-11, E-08028 Barcelona, Spain \\ E-mail: oriol.rossell@qi.ub.es; miquel.seco@qi.ub.es \\ Anne-Marie Caminade and Jean-Pierre Majoral \\ Laboratoire de Chimie de Coordination du CNRS, 205, Route de Narbonne, 31077 Toulouse Cedex 4, France \\ E-mail: caminade@lcc-toulouse.fr;majoral@lcc-toulouse.fr
}

Received: 23 April 2001

The synthesis of dendrimers possessing gold atoms on the surface or inside the internal layers is reported. They have been shown to be precursors to mixed gold-transition metal cluster-containing dendrimers, which represent a new class of hybrid materials. The latter species are rather soluble in common solvents and can be characterized by spectroscopic methods. Moreover, gold-containing dendrimers are useful for making gold nanoparticles, which have very interesting electronic, optical, and catalytic properties.

There is currently considerable interest in the development of dendrimers, which are well-defined highly branched macromolecules that emanate from a central core (1). They are formed by iterative reaction sequences and their size, topology, flexibility and molecular weight can be precisely controlled during manufacture, in clear contrast to 'classical' polymers. In these, the unrestricted manner in which one monomer is covalently attached to another generally results in average molecular weights and nondiscrete topologies. Interestingly, the presence of a large number of chainend and internal voids in dendrimers allows, for example, the encapsulation of guest molecules or molecular recognition at specific locations on the cascade superstructure.

On the other hand, metalladendrimers constitute a very interesting class of these species because of their useful properties in areas such as catalysis, electrochemistry, and photophysics, among others (2). Metal centres can be grafted onto the surface or within dendrimers and have been shown to act as connectors or branching centres. Among all the metalladendrimers reported to date, very little is known about dendrimerbased multinuclear gold(I) complexes, and the purpose of this report is to update the knowledge in this area.

\section{SYNTHESIS OF GOLD-CONTAINING DENDRIMERS}

The gold fragment $\mathrm{AuCl}$ was first introduced at the core of a polycationic phosphorus-containing dendrimer of generation two, using the reactions indicated in Scheme 1 (3): reduction of the phosphine oxide core of the dendrimer using trichlorosilane, followed by the coordination of the resulting phosphine core by $\mathrm{Au}(\mathrm{I})$, using sodium tetrachloroaurate (Scheme 1).

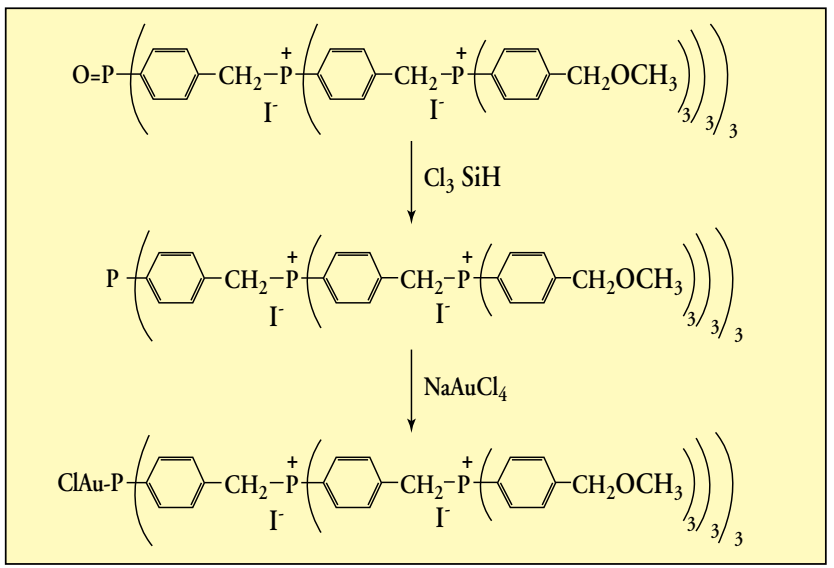

Scheme 1 


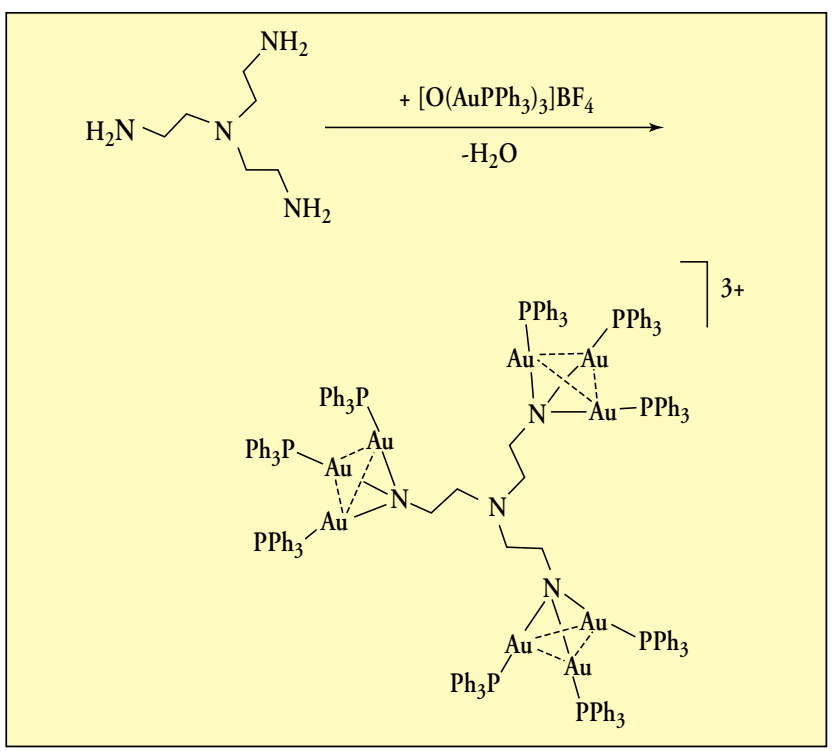

Scheme 2

Reaction of a dendritic polyethyleneimine species with the oxonium reagent $\left[\mathrm{O}\left(\mathrm{AuPPh}_{3}\right)_{3}\right]^{+} \mathrm{BF}_{4}^{-}$(4) allows the incorporation of gold on the surface of the dendrimer (Scheme 2).

However, the vast majority of gold-containing dendrimers have been prepared by taking advantage of the complexation ability of the phosphine-terminated dendrimers (Reaction (1)):

$$
\begin{gathered}
\text { dendr }-\mathrm{PPh}_{2}+\mathrm{ClAuL} \longrightarrow \text { dendr }-\mathrm{PPh}_{2} \mathrm{AuCl}+\mathrm{L} \\
\mathrm{L}=\text { tetrahydrothiophene }(\text { tht }), \mathrm{Me}_{2} \mathrm{~S}
\end{gathered}
$$

The functionalization of dendrimers with phosphine ligands, which can be carried out via the reactions shown in Scheme 3, is the key for the subsequent grafting of the gold fragments to the surface.

Accordingly, Schmidbaur and co-workers (5) have reported two examples of gold-containing dendrimers based on amino-terminated cascades, following the approach outlined in the Scheme 4.

Thus, the third- and fourth-generation diaminobutane-poly(trimethyleneamine)s (DAB-PPI $\left(\mathrm{NH}_{2}\right)_{\mathrm{n}}, \mathrm{n}=16$ or 32) were treated with $\beta$ (diphenylphosphino)propionic acid to give the

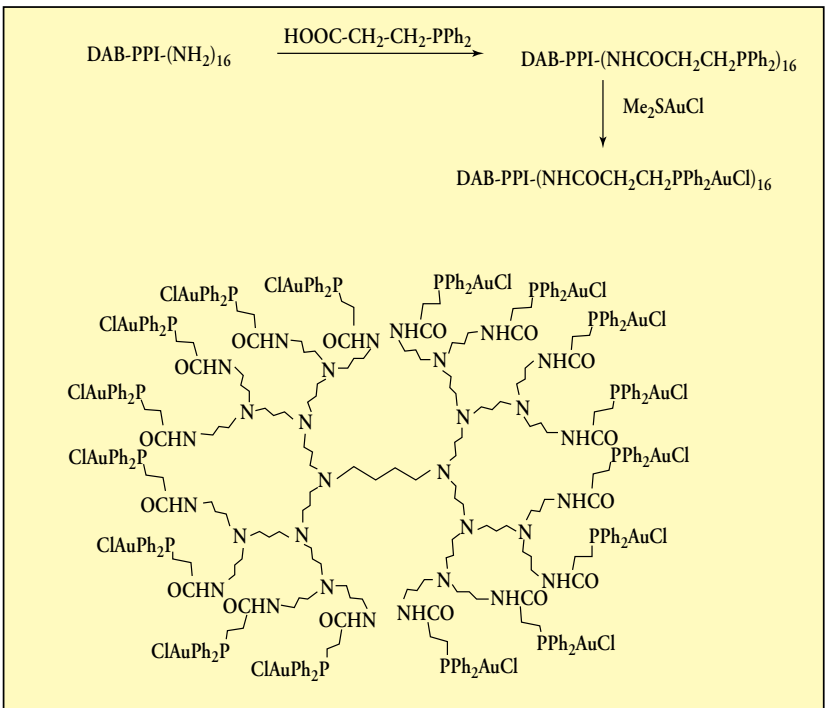

Scheme 4

diphenylphosphino-terminated dendrimers, whose subsequent treatment with $\left(\mathrm{Me}_{2} \mathrm{~S}\right) \mathrm{AuCl}$ afforded the corresponding Au-substituted dendrimers.

A large number of phosphine-terminated dendrimers have been reported by Majoral and coworkers (6), some of which have been decorated on the periphery by gold fragments.

Scheme 5 shows the complete formation of the largest polyphosphine gold complexes of well-defined structure reported to date (7). In this dendrimer, the surface is covered theoretically by $3072 \mathrm{AuCl}$ moieties.

Gold complexes of generation 3, 4, 5, and 10 were imaged by high resolution electron microscopy in order to compare the size of consecutive generations and to see whether higher order structures had been formed. Isolated spheres with measured diameters of approximately 60, 75, 90 and $150 \AA$, respectively, were observed (Figure 1).

In addition to the coverage of the surface of the dendrimers with phosphine chains, two examples of regioselective gold complexation into internal layers of dendritic and polydendritic macromolecules have been reported. Scheme 6 shows that two PNPS linkages are first introduced into the cascade structure of a dendrimer of generation 1 and subsequent addition of 2 equivalents

\begin{tabular}{|c|c|}
\hline $\begin{array}{r}\text { dendr }-\mathrm{NH}_{2}+\mathrm{HOOC}-\mathrm{C}_{2} \mathrm{H}_{4}-\mathrm{PPh}_{2} \\
\text { l } \\
\text { dendr- }{ }_{1}^{\mathrm{Si}-\mathrm{Cl}}+\mathrm{LiCH}_{2}-\mathrm{PPh}_{2} \\
\text { dendr- } \mathrm{CH}=\mathrm{N}-\mathrm{NHMe}+\mathrm{PPh}_{2}-\mathrm{CH}_{2} \mathrm{OH}\end{array}$ & $\begin{array}{l}d e n d r-\mathrm{NHOC}-\mathrm{C}_{2} \mathrm{H}_{4}-\mathrm{PPh}_{2} \\
\text { । } \\
d e n d r-\mathrm{S}-\mathrm{CH}_{2}-\mathrm{PPh}_{2} \\
d e n d r-\mathrm{CH}=\mathrm{N}-\mathrm{N}(\mathrm{Me})-\mathrm{CH}_{2}-\mathrm{PPh}_{2}\end{array}$ \\
\hline
\end{tabular}
of $\mathrm{AuCl}(\mathrm{tht})$ gives the dinuclear complex (8).

Scheme 3 


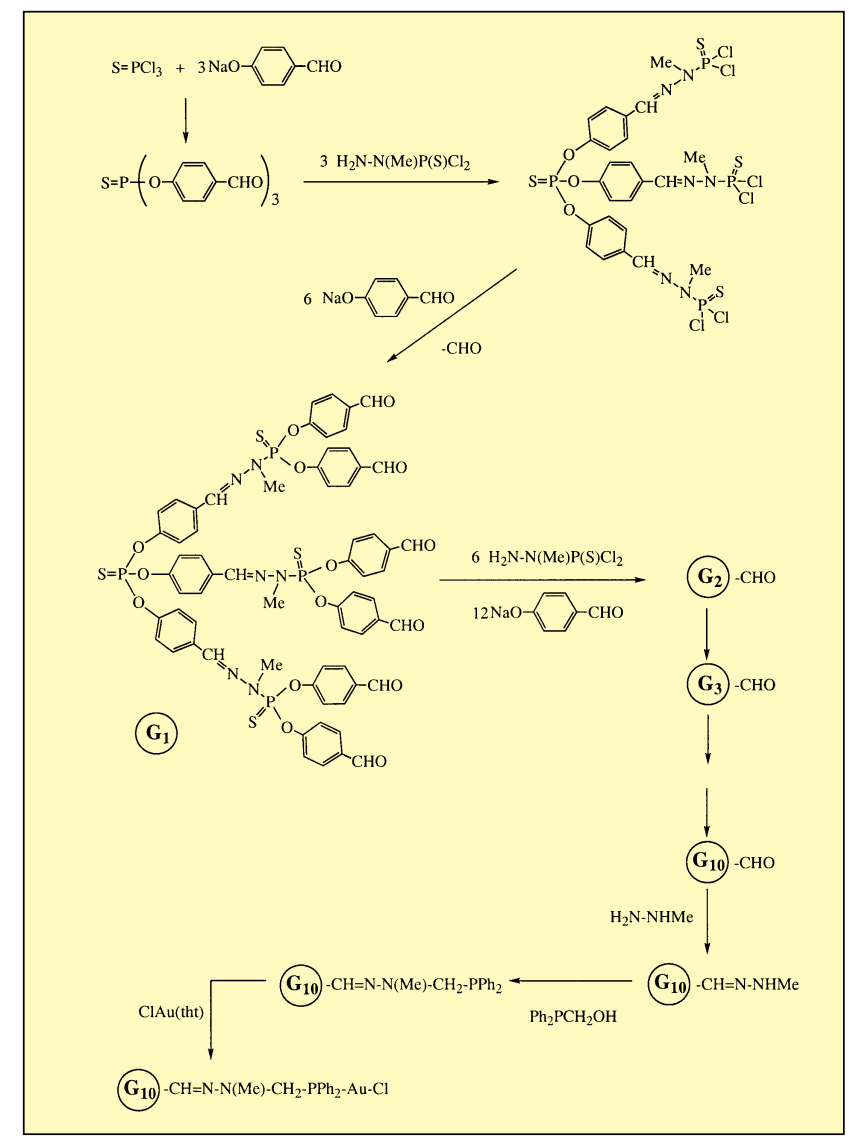

Scheme 5

Another example with complexation taking place simultaneously on a nonconventional PNPNPS fragment and on one more classical $\mathrm{CH}_{2} \mathrm{PPh}_{2}$ moiety is depicted in Scheme 7.

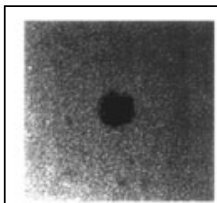

a

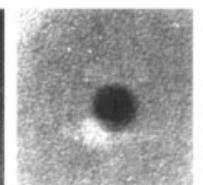

b

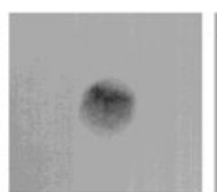

c

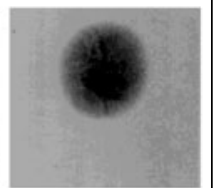

d
Figure 1 High-resolution transmission electron micrographs of dendrimers $G_{n}-\mathrm{CH}=\mathrm{N}-\mathrm{N}(\mathrm{Me})-\mathrm{CH}_{2}-\mathrm{PPh}_{2}-\mathrm{Au}-\mathrm{Cl}$. (a) $n=3$, (b) $n=4$, (c) $n=5$, (d) $n=10$

\section{REACTIVITY OF GOLD/ DENDRIMER SPECIES: SYNTHESIS OF GOLD- TRANSITION METAL CLUSTER- CONTAINING DENDRIMERS}

The presence of one chloride atom bonded to each gold atom of the surface has suggested assessment of the

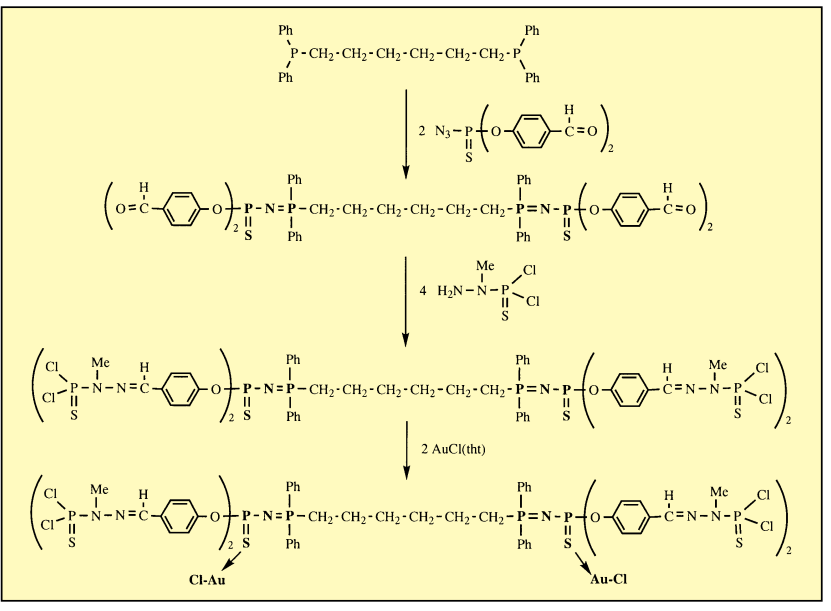

Scheme 6

reactivity of this type of species. Indeed, it is well-known that $\mathrm{LAu}-\mathrm{Cl}$ complexes display versatile reactivity. For instance, they react easily with RLi or Grignard reagents to afford the corresponding LAu-R complexes. Consequently, it is not surprising that the dendrimer $\mathrm{G}_{4}-\mathrm{CH}=\mathrm{N}-\mathrm{N}(\mathrm{Me})-\mathrm{CH}_{2}-\mathrm{PPh}_{2}-\mathrm{Au}-\mathrm{Cl}$ (Scheme 5) reacts with the alkylating agent $\mathrm{Cp}_{2} \mathrm{ZrMe}_{2}$ to give the corresponding gold-methyl derivative (9).

More interestingly, $\mathrm{LAu}-\mathrm{Cl}$ proved to be an excellent precursor for the synthesis of mixed transition-metal clusters. Thus, taking into account that $\mathrm{ClAuPPh}_{3}$ has been shown to react with a number of metal anions, such as $\left[\mathrm{Fe}_{2}(\mathrm{CO})_{7}\left(\mathrm{PPh}_{2}\right)\right]^{-}$or $\left[\mathrm{Fe}_{3}(\mathrm{CO})_{11}\right]^{2-}$, to give the mixed transition metal clusters $\left[\mathrm{Fe}_{2} \mathrm{Au}(\mathrm{CO})_{7}\left(\mathrm{PPh}_{2}\right)\right]$ and $\left[\mathrm{Fe}_{3} \mathrm{Au}(\mathrm{CO})_{11}\left(\mathrm{PPh}_{3}\right)\right]^{-}(10)$, respectively, the carbosilane dendrimer $\quad \mathrm{Si}\left(\mathrm{CH}_{2} \mathrm{CH}_{2} \mathrm{Si}(\mathrm{Me})_{2} \mathrm{CH}_{2} \mathrm{CH}_{2} \mathrm{Si}(\mathrm{Me})\right.$ $\left.\left(\mathrm{CH}_{2} \mathrm{CH}_{2} \mathrm{Si}(\mathrm{Me})_{2} \mathrm{CH}_{2} \mathrm{PPh}_{2} \mathrm{AuCl}\right)_{2}\right)_{4}$ was treated with these iron anions to afford the first cluster-containing dendrimers (11) (Scheme 8). For X $=\mathrm{PPh}_{2}$, the metal core consists of an $\mathrm{Fe}_{2} \mathrm{Au}$ triangular cluster, while for $\mathrm{X}=\mathrm{Fe}(\mathrm{CO})_{4}$, the metal geometry can be regarded as an $\mathrm{Fe}_{3} \mathrm{Au}$ butterfly arrangement, in which the gold atom bridges one edge of the $\mathrm{Fe}_{3}$ triangle. It is remarkable that the presence of $\mathrm{CH}_{2} \mathrm{CH}_{2} \mathrm{SiMe}_{2}$ units as spacers dramatically increases the solubility of this type of species and that, consequently, they could be analysed spectroscopically.

Following the same strategy, the synthesis of new mixed molybdenum- or manganese/gold clustercontaining dendrimers was accomplished by the reaction between the phosphorus-terminated carbosilane dendrimer and the corresponding metal anion (12) (Scheme 9).

In order to extend this type of reaction to other 


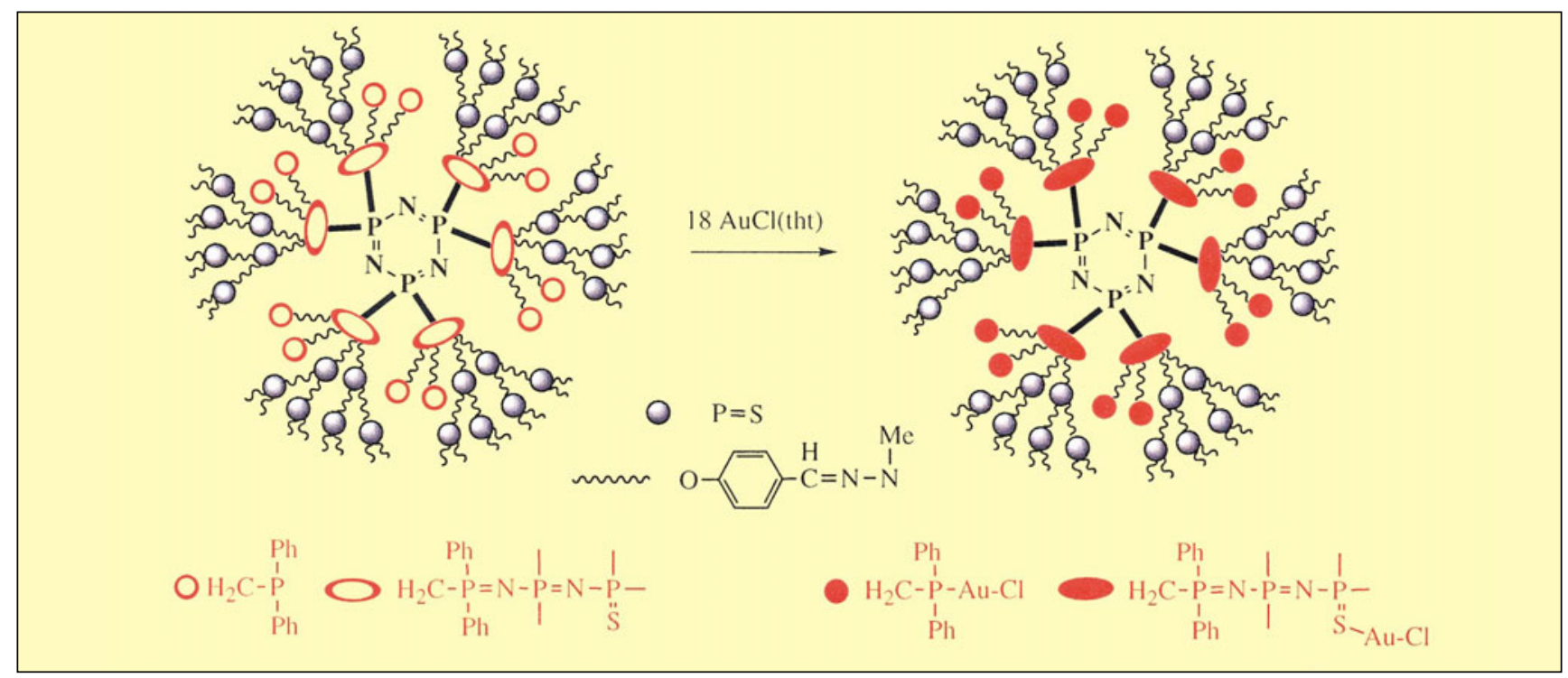

Scheme 7

gold-containing dendrimers, $\left(\mathrm{NEt}_{4}\right)\left[\mathrm{Fe}_{2}(\mathrm{CO})_{7}\left(\mathrm{PPh}_{2}\right)\right]$ was added to a solution of the gold-decorated dendrimers derived from $G_{3}$ and $G_{6}$, depicted in Scheme 5, to afford the species containing 24 and 192 metal cluster groups, respectively (13) (Scheme 10). These reactions were monitored by ${ }^{31} \mathrm{P}-\mathrm{NMR}$ spectroscopy and the resulting complexes are pure within the limits of the NMR spectroscopic detection.

Starting from [DAB-dendr- $\left.\left\{\mathrm{N}\left(\mathrm{CH}_{2} \mathrm{PPh}_{2}\right)_{2}\right\}_{16}\right]$ it was possible to construct a molecular dendrimer displaying a multiple layer structure (Scheme 11). The cluster metal core consists of an $\mathrm{Ru}_{6}$ octahedron in which two adjacent edges are bridged by the gold

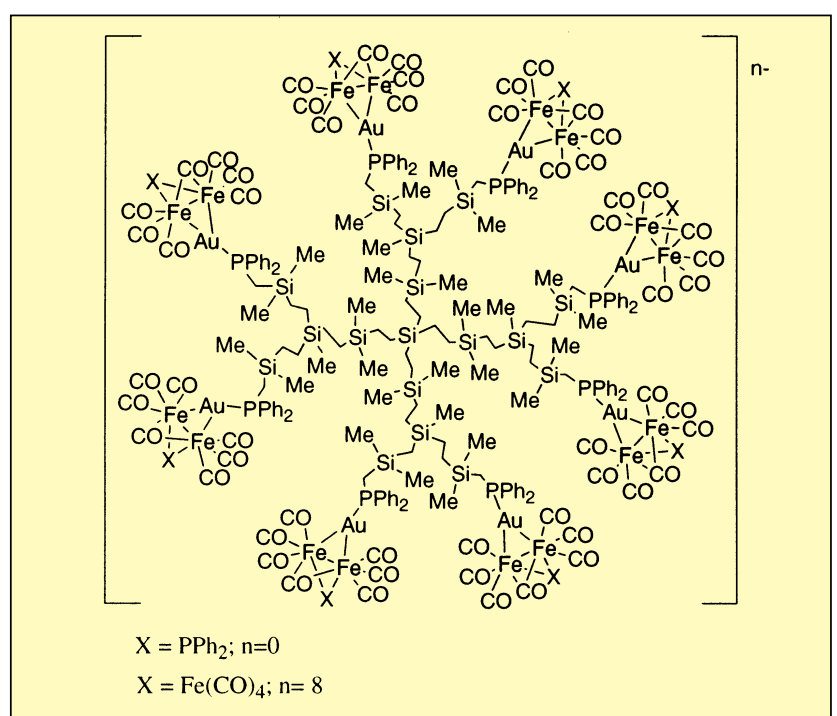

Scheme 8 atoms, which are separated by $2.9362 \AA$ (14).

From a structural point of view, the hybrid cluster/dendrimers depicted above can be seen as spheres consisting of a nonconducting organic core with a sheath of conducting metal particles over the surface, which in turn is covered by a further outer layer of insulating carbonyl ligands. For conduction, an electron introduced into the molecule would first have to tunnel through the carbonyl sheath to the 'metallic layer', move through the metallic layer to an exit point, and then tunnel again out of the molecule (14).

It is worth noting that the reaction of a thiolterminated fourth generation dendrimer $(96 \mathrm{SH}$ groups) with the gold cluster compound

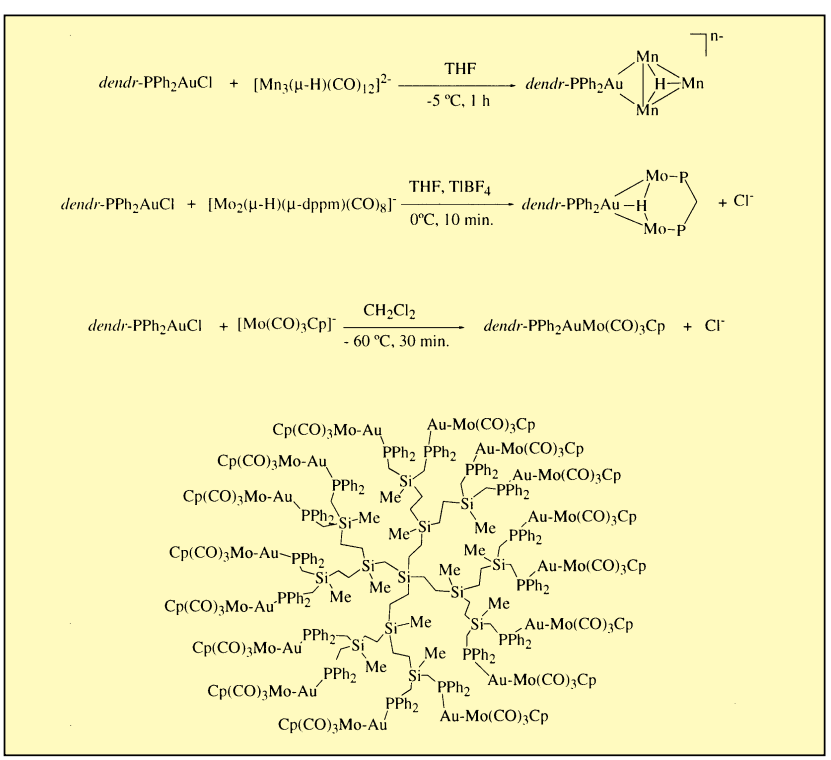

Scheme 9 


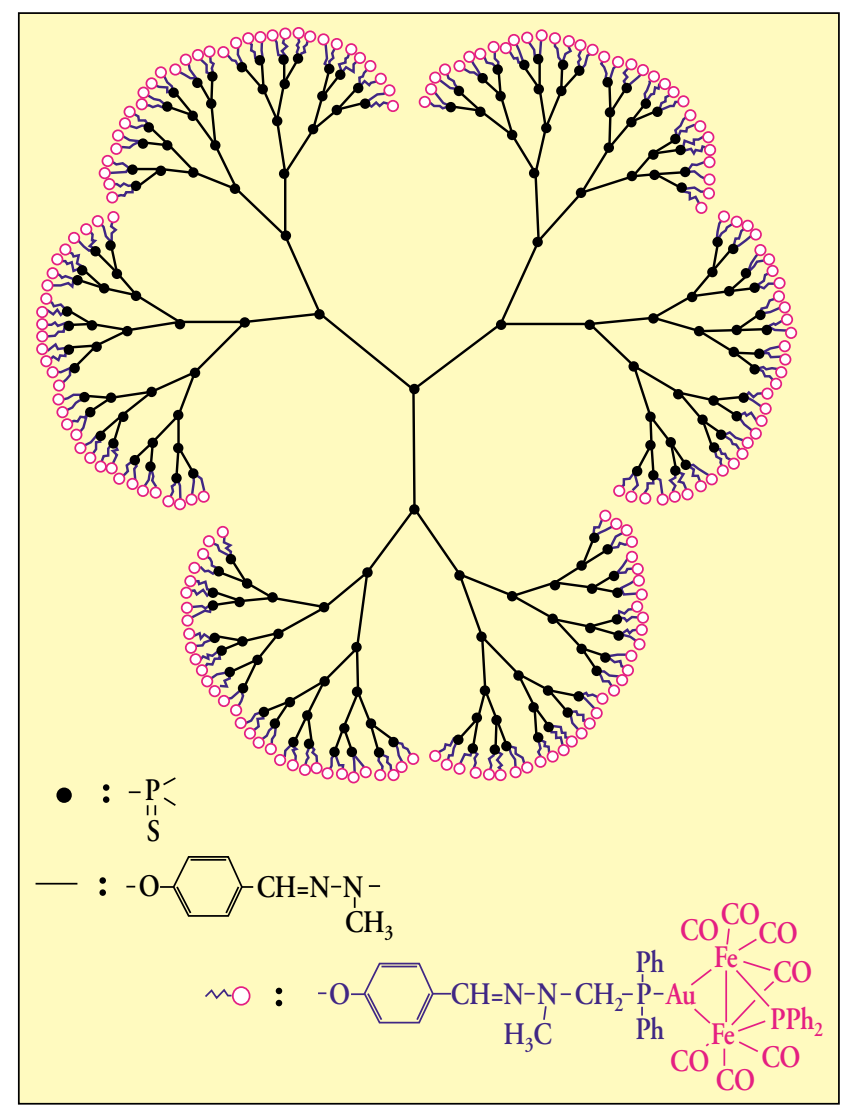

Scheme 10

$\mathrm{Au}_{55}\left(\mathrm{PPh}_{3}\right)_{12} \mathrm{Cl}_{6}$ in a 3:1 molar ratio in dichloromethane results in the unprecedented and unexpected formation of bare $\mathrm{Au}_{55}$ clusters (15). The cubooctahedrally shaped $\mathrm{Au}_{55}$ particles coalesce to well-

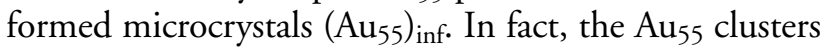
act as building blocks in $\left(\mathrm{Au}_{55}\right)_{\text {inf }}$ superstructures. The role of the dendrimer is not only to remove the phosphine and chlorine ligands but also to act as an ideal matrix for perfect crystal growth. TEM images indicate that the crystal is coated with a thin film which is thought to consist of dendrimer material.

\section{CHARACTERIZATION OF GOLD- DENDRIMERS}

The characterization of metallodendrimers, and particularly gold/dendrimers, is not trivial. To the difficulty of growing single crystals for X-ray structure determination (they were obtained only for the first generation) is added the impossibility in many cases of obtaining satisfactory mass spectra. Mass spectrometry (FAB) generally allows characterization of dendrimers

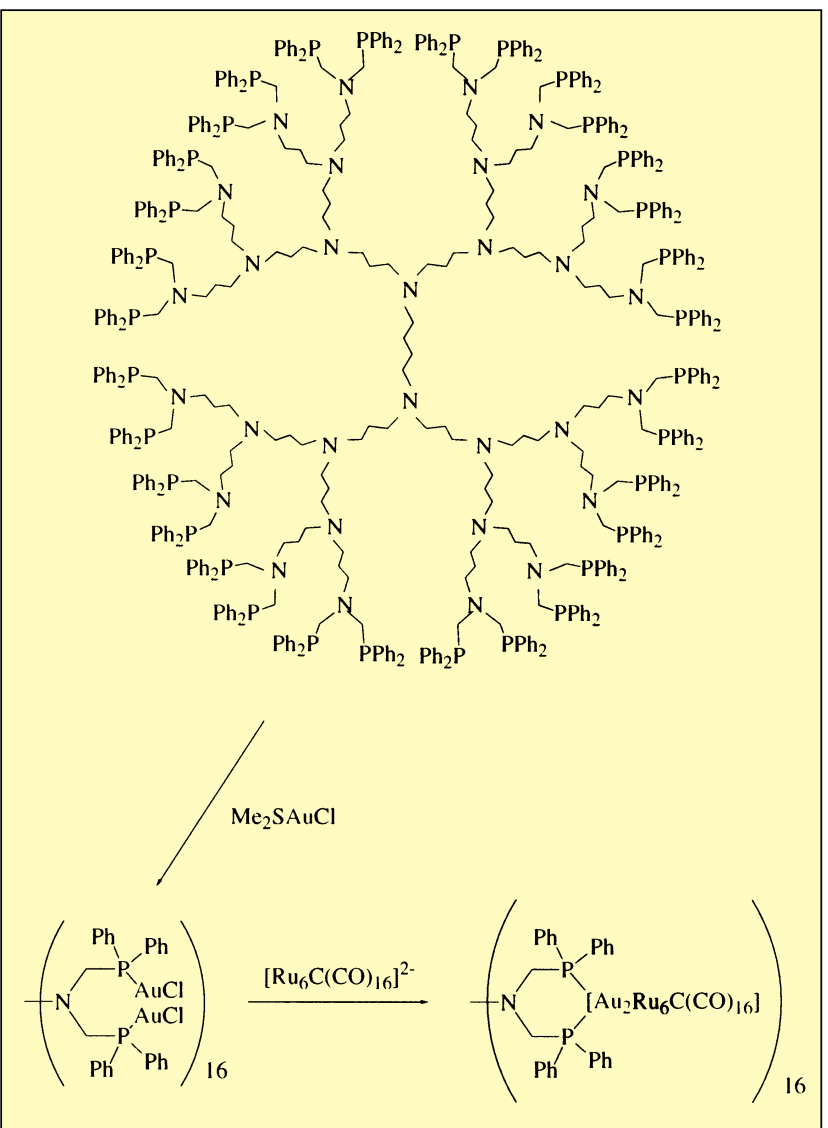

Scheme 11

up to generation 2 or 3 . On the other hand, MALDITOF should be the best tool to prove that the preparation of metallodendrimers has been achieved. However, laser irradiation can provoke cleavage of some gold fragments, precluding identification of the parent molecular peak, and suitable experimental conditions have not yet been found. Other characterization methods include intrinsic viscosity, DSC-TGA, and size-exclusion chromatography.

However, the most powerful method for the characterization of such species is NMR spectroscopy. ${ }^{31} \mathrm{P}$ NMR spectroscopy has been shown to be an extraordinarily useful tool for following the growth of phosphorus-containing dendrimers and for controlling the progress of the reactions. However, it should be noted that structure defects cannot be detected in the limit of ${ }^{31} \mathrm{P}$ NMR precision (about $1 \%$ ). ${ }^{29} \mathrm{Si}$ NMR spectra are particularly appropriate in the characterization of the gold-cluster-containing carbosilane dendrimers, such as those depicted in Scheme 9, since they display clearly separated signals for the different types of silicon atoms in the molecules (Figure 2). 


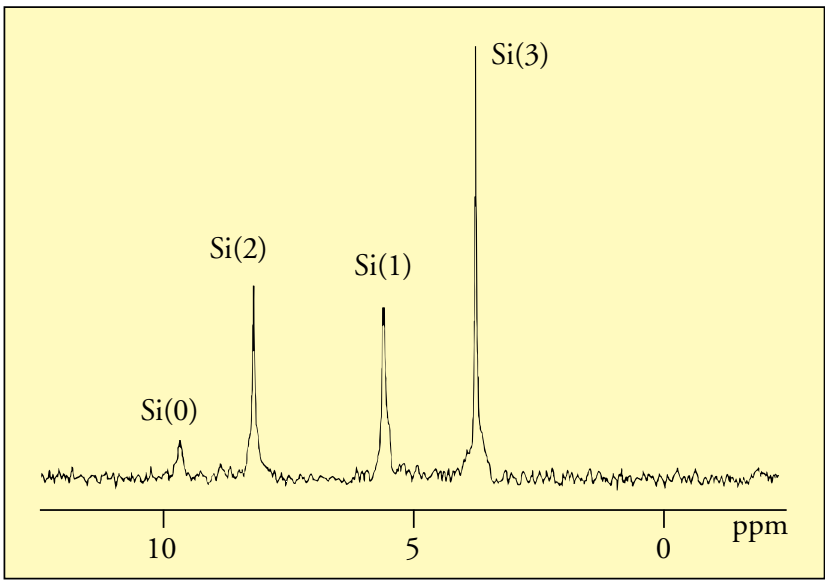

Figure $2{ }^{29} \mathrm{Si}\left\{{ }^{1} H\right\}-N M R$ spectrum of the third generation dendrimer containing eight $\mathrm{Mo}_{2} \mathrm{Au}$ units

\section{GOLD COLLOIDS AND DENDRIMERS}

Metal nanoclusters have attracted widespread interest since their nanosize physical properties are quite different from those of the bulk materials, depending upon their size and the extent of aggregation, shape, and packing density. The potential applications for nanoclusters include catalysts, biochemical sensors, quantum dots, nanostructure fabrication, and optoelectronic devices. For example, $\mathrm{Pd} / \mathrm{Au}$ particles have been used as hydrogenation catalysts (16) while gold particles catalyse the oxidation of carbon monoxide (17). The use of dendrimers has emerged as an area of great interest over the past few years for nanocluster synthesis. This is because they are now recognized as a nanoscale template/stabilizer/container in the synthesis and stabilization of inorganic clusters by reaction of preorganized reactants in the dendrimer interior. Thus, gold colloids in the $2-3 \mathrm{~nm}$ size range can be easily and reproducibly prepared by in situ reduction of $\mathrm{HAuCl}_{4}$ in the presence of poly(amidoamine) dendrimers (18). The nano templating by dendrimers in aqueous solution is depicted schematically in Figure 3 (19).

The addition of $\mathrm{HAuCl}_{4}$ to a neutral dendrimer with primary and tertiary amine groups results in a protonated dendrimer with $\mathrm{AuCl}_{4}^{-}$counterions. The gold ions are then reduced to metallic gold using $\mathrm{NaBH}_{4}$ without the formation of a macroscopic metal precipitate. The stable brown to red solutions of colloidal gold formed indicate that the metal colloids are stabilized by the dendrimer. The dendrimer acts, in fact, as a template to hold a particular number of ions in close proximity prior to reduction, and subsequently as a nanoporous stabilizer to prevent particle

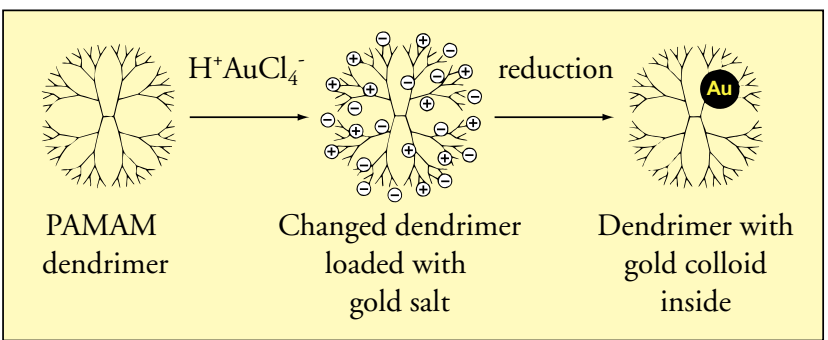

Figure 3 Dendrimer nanotemplating in aqueous solution (adapted from reference 19)

agglomeration. The dendrimer generation used in the synthesis controls the size of the resulting colloids: lowergeneration dendrimers give rise to larger colloids. In addition to this, the size of the particles depends on the ratio of the gold ions added to dendrimer, the dendrimer concentration in solution, and the reduction rate.

Gold colloids have also been prepared, in the presence of poly(amidoamine) dendrimers with surface amino groups, by reduction of $\mathrm{HAuCl}_{4}$ with UV irradiation (20) or by using hydrazine (21).

Interestingly, it has been demonstrated that dendrimer encapsulated nanoclusters can be prepared by in situ exchange of a dendrimer-encapsulated metal particle for a different, more noble metal. For example, copper or silver clusters can be displaced by gold (22). This method can lead to composite materials in which metal particles and chemically distinct metal ions coexist within individual dendrimers; such materials may have unique properties for catalysis.

Now that the properties of metal-dendrimer nanomaterials have been defined, methods to assemble these materials to form well-defined thin films have been explored. Basically, the synthetic route for colloidal films is illustrated in Figure 4 (23).

In the first step the surface, such as glass or silicon oxide, is modified with dendrimer molecules. In the second, the dendrimer-modified substrate is immersed into the gold colloid solutions resulting in stable deposition of the gold particles onto the surface. The final colloid-coated substrate shows a continuous redviolet film. In general, the size distribution, particle separation, and degree of colloid monolayer formation can be controlled and studied by X-ray photoelectron spectroscopy (XPS), scanning electron microscopy (SEM), and atomic force microscopy (AFM).

\section{CONCLUSIONS}

The number of gold-containing dendrimers and dendrimers grafted with gold-transition metal clusters on 


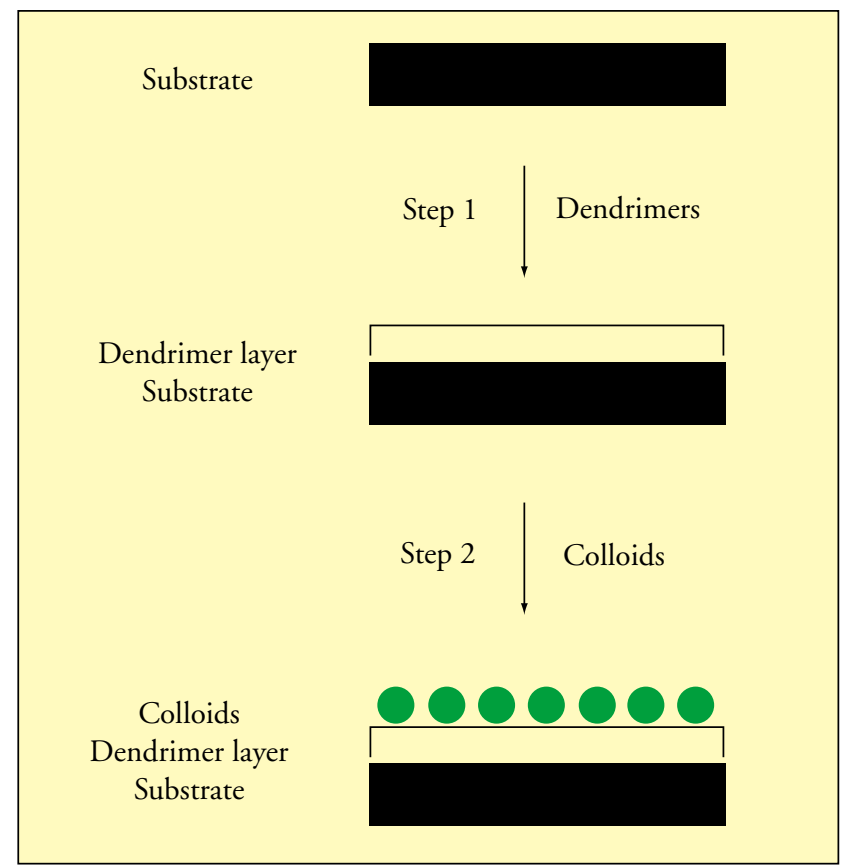

Figure 4 Schematic representation of the synthetic route for colloid monolayer preparation (adapted from reference 23)

the periphery reported to date is still low compared with other metallodendrimers. With few exceptions, the gold atoms appear to be bonded to the surface of the dendrimer through a phosphorus atom and their characterization can be carried out using standard spectroscopic techniques.

Although it is still too soon to make predictions about the potential use of these species, it is clear that the employment of gold dendrimers as intermediates for the synthesis of nanoscale gold particles will increase exponentially because of the fascinating properties of the latter in areas such as optics, electronics and catalysis.

\section{ABOUT THE AUTHORS}

Oriol Rossell joined the Departament de Química Inorgànica of the University of Barcelona in 1972, where since 1992 he has been full professor of Inorganic Chemistry. Miquel Seco received his Ph.D from the University of Barcelona in 1981, where he is now professor titular. Their main research is in transition metal cluster chemistry.

Jean-Pierre Majoral has been Director of Research at the CNRS in Toulouse since 1978. His main research interests lie in dendrimer chemistry and applications and on the use of Group 4 elements in organic, organometallic and heteroatom chemistries. Anne-Marie Caminade has been Director of Research at the CNRS in Toulouse since 1997. Her main research interests focus on dendrimer chemistry and applications, and also on phosphorus chemistry.

\section{REFERENCES}

1 G.R. Newkome, C.N. Moorefield and F. Vögtle, 'Dendritic Molecules', VCH, Weinheim, 1996. J.-P. Majoral and A.-M. Caminade, Chem. Rev., 1999, 99, 845

2 For reviews see, for example: D.A. Tomalia and H.D. Durst, in Top. Curr. Chem., ed. E. Weber, Springer, Berlin, 1993, pp. 193-313. G.R. Newkome, E. He, C.N. Moorefield, Chem. Rev., 1999, 99, 1689

3 R. Engel, K. Rengan and C.S. Chan, Heteroatom Chem., 1993, 4, 181

4 P. Lange, H. Beruda, W. Hiller and H. Schmidbaur, Z. Naturforsch, 1994, 49b, 781

5 P. Lange, A. Schier and H. Schmidbaur, Inorg. Chem., 1996, 35, 637

6 A.M. Caminade, R. Laurent, B. Chaudret and J.-P. Majoral, Coord. Chem. Rev., 1998, 178-180, 793

7 M. Slany, M. Bardají, M.J. Casanove, A.-M. Caminade, J.-P. Majoral and B. Chaudret, J. Amer. Chem. Soc. 1995, 117, 9764

8 C. Larré, B. Donadieu, A.-M. Caminade and J.-P. Majoral, Chem. Eur. J., 1998, 4(10), 2031

9 M. Slany, M. Bardají, A.-M. Caminade, B. Chaudret and J.-P. Majoral, Inorg. Chem., 1997, 36, 1939

10 M. Ferrer, R. Reina, O. Rossell and M. Seco, Coord. Chem. Rev., 1999, 193-195, 619

11 M. Benito, O. Rossell, M. Seco and G. Segalès, Organometallics, 1999, 18, 5191

12 M. Benito, O. Rossell, M. Seco and G. Segalès, J. Organomet. Chem., 2001, 619, 245

13 M. Benito, O. Rossell, M. Seco, G. Segalès, V. Maraval, R. Laurent, A.-M. Caminade and J.-P. Majoral, J. Organomet. Chem., 2001, 622, 33

14 N. Feder, J. Geng, P.G. Goh, B.F.G. Johnson, C.M. Martin, D.S. Shephard and W. Zhou, Angew. Chem. Int. Ed., 2000, 39(9), 1661

15 G. Schmid, W. Meyer-Zaika, R. Pugin, T. Sawitowski, J.-P. Majoral, A.-M. Caminade and C-O. Turrin, Chem. Eur. J., 2000, 6(9), 1693

16 M.N. Vargaftik, V.P. Zagorodnikov, I.P. Stolarov, I.I. Moiseev, D.I. Kochubey, V.A. Likholobov, A.L. Chuvilin and K.I. Zamaraev, J. Mol. Cat., 1989, 53, 315

17 M. Haruta, T. Kobayashi, H. Sano and N. Yamada, Chem. Lett., 1987, 405

18 M.E. García, L.A. Baker and R.M. Crooks, Anal. Chem., 1999, 71, 256

19 F. Gröhn, B.J. Bauer, Y.A. Akpalu, C.L. Jackson and E.J. Amis, Macromolecules, 2000, 33, 6042

20 K. Esumi, A. Suzuki, N. Aihara, K. Usui and K. Torigoe, Langmuir, 1998, 14, 3157

21 J-A. He, R. Valluzzi, K. Yang, T. Dolukhanyan, C. Sung, J. Kumar and S.K. Tripathy, Chem. Mater., 1999, 11, 3268

22 M. Zhao and R.M. Crooks, Chem. Mater., 1999, 11, 3379

23 G. Bar, S. Rubin, R.W. Cutts, T.N. Taylor and T.A. Zawodzinski, Langmuir, 1996, 12, 1172 